\title{
Diferença dos Relatos de Experiência em Docência entre Alunos do Estágio Curricular Supervisionado e Programa Residência Pedagógica
}

Difference in Teaching Experience Reports among Supervised Internship Students and Pedagogical Residency Program

Francisca Cassia Sousa dos Anjos
Oséias Soares Ferreira
Diego Arantes Teixeira Pires

Resumo: A experiência em docência é uma etapa essencial para a formação de professores, podendo estar diretamente relacionada com a qualidade do ensino. Nesse sentido, os licenciados podem ter experiência na educação básica, ao longo do curso, pelos estágios curriculares supervisionados ou pelo Programa Residência Pedagógica, etapas que visam o contato com a docência. Neste trabalho, analisou-se as respostas de um questionário, aplicado a alunos estagiários e residentes, para observar as diferenças nos relatos de experiência em docência. Notou-se que os dois grupos destacaram pontos positivos e dificuldades semelhantes e, percebeu-se também, que a experiência com o Programa Residência Pedagógica pode ser uma boa oportunidade para aperfeiçoar a atividades dos estágios supervisionados.

Palavras-chave: Formação de professores. Residência Pedagógica. Estágio. Docência.

Abstract: The teaching experience is an essential step for the teacher training and can be directly related to the quality of classes. In this sense, graduation students may have experience in basic education during the course through supervised internships or through the pedagogical residency program. These steps aim the contact with teaching. In this work, the responses of a questionnaire, applied to trainee and resident students, were analyzed to observe the differences in the reports of teaching experience. It was noted that both groups highlighted positive aspects and similar difficulties, and it was also realized that the experience with the pedagogical residency program can be a good opportunity to improve the activities of the supervised internships.

Keywords: Teacher training. Pedagogical Residence. Supervised Internship. Teaching.

\section{Introdução}

Não é difícil encontrar professores recém-formados que chegam às salas de aula com pouca experiência e se deparam com uma realidade muito diferente da que se esperava ou estudava (GUEDES, 2019; FARIA; PEREIRA, 2019). Com isso, em alguns casos, pode-se notar docentes assustados com a realidade escolar, incorrendo inclusive na desistência desses professores da profissão docente. Desta forma, percebe-se o quanto é relevante a 
oportunidade de se aproximar da realidade escolar durante a graduação, destacando a importância da experiência em docência para os futuros profissionais (GUEDES, 2019; FARIA; PEREIRA, 2019).

O Conselho Nacional de Educação (CNE) definiu em 2015 as novas Diretrizes Curriculares Nacionais para a formação inicial de professores em nível superior, destacando a formação de professores e sua relação com a qualidade do ensino, bem como a importância da experiência em docência ao longo de um curso de Licenciatura (BRASIL, 2015). Essa resolução estipula que os cursos de Licenciatura devem apresentar uma carga horária mínima de 400 horas dedicadas ao estágio curricular supervisionado na área de formação e de atuação na educação básica. A resolução também destaca que o estágio curricular supervisionado deve ser um componente obrigatório, devendo ser uma atividade específica intrinsecamente articulada com a prática, proporcionando, ao longo da formação, ampla articulação entre teoria e prática e a obrigatoriedade de se levar em conta a realidade dos ambientes das instituições educativas da educação básica e da profissão docente.

Para Pimenta e Lima (2017) e Kasseboehmer e Ferreira (2008), o estágio curricular supervisionado em docência é uma etapa de extrema importância para a formação de professores, que faz com que os estudantes tenham a interação e aplicação das práticas educativas estudadas. Nesse sentido, para os autores, não há como um estudante de licenciatura separar a teoria da prática, ou seja, a teoria precisa da prática e a prática precisa da teoria, e o estágio pode proporcionar esse elo ao futuro professor.

O entendimento sobre estágio supervisionado obrigatório é que esse não deve ser entendido apenas como mais uma disciplina no curso, mas deve ser constituído como um campo do conhecimento, proporcionando experiência de estudos científicos e desenvolvendo as práticas e ações educativas aprendidas durante a formação na universidade (PIMENTA; LIMA, 2017; KASSEBOEHMER; FERREIRA, 2008). Além disso, os autores destacam alguns relatos de professores recém-formados que afirmam ser a realidade escolar observada ao longo dos estágios supervisionados completamente distinta da trabalhada na teoria, evidenciando, com isso, a importância da 
experiência em docência ao longo da graduação para formação de professores. A experiência em sala de aula ao longo da formação pode ser muito importante para contornar possíveis "visões distorcidas" do ambiente escolar de educação básica e melhor preparar o licenciando para a prática docente, fornecendo-os uma formação sólida.

Pimenta e Lima (2017) afirmam que a formação dada nas faculdades e universidades no Brasil, muitas vezes, não transmite a realidade que deu origem aos currículos de formação de professores, indicando a grande divergência do conhecimento disciplinar com a atuação que será executada pelos futuros docentes. Assim, Piconez e colaboradores (1991) destacam um hiato entre teoria e prática, apontando que os novos professores se formam com uma ampla bagagem teórica, todavia, a maioria mostra-se incapaz de associar o conhecimento teórico com a prática em docência. Para tanto, o estágio curricular supervisionado pode ter uma alternativa para quebrar essa dicotomia.

A experiência em docência que os estágios supervisionados podem trazer é inquestionável. Entretanto, Piconez e colaboradores (1991) e Silva e Schnetzler (2011) defendem a existência de uma relação dialética entre o estágio curricular e a prática de ensino no contexto da educação brasileira, visto que os estudantes de licenciatura podem ter experiências docentes com professores que já estão atuando em sala de aula há mais tempo e, porventura, tiveram uma formação tradicional (e não se preocuparam com uma formação continuada). Com isso, o licenciando pode acompanhar uma prática de ensino distante da estudada nas instituições de ensino superior. Nessa perspectiva, destaca-se a importância dos laços entre as instituições de educação básica com as instituições de ensino superior para melhor proporcionar uma formação inicial e continuada ao docente. Para Pimenta e Lima (2017), Garcez et al. (2012) os futuros professores podem inclusive se tornar pesquisadores, e seguirem na docência, não apenas observando problemas, mas resolvendo os problemas e adversidades que podem encontrar ao longo da profissão. 
O estágio pode proporcionar um contato direto do licenciando com a realidade escolar. Segundo Freire (2013) ação humana não se separa da realidade objetiva, reafirmando que o tempo de permanência e de contato com os alunos, bem como sistema comum das escolas, podem dar o embasamento e a segurança que o futuro professor precisará na sua atuação educacional.

A experiência em docência e os estágios supervisionados devem ser assuntos sempre discutidos e repensados nos cursos de formação de professores. Desta forma, o primeiro edital da Coordenação de Aperfeiçoamento de Pessoal de Nível Superior (CAPES) para o Programa Residência Pedagógica foi lançado em 2018 (BRASIL, 2018), visando estimular a articulação entre teoria e prática nos cursos de licenciatura, conduzindo uma parceria com as redes públicas de educação básica.

O Programa Residência Pedagógica (PRP) apresenta quatro objetivos principais, que são:

I. Aperfeiçoar a formação dos discentes de cursos de licenciatura, por meio do desenvolvimento de projetos que fortaleçam o campo da prática e conduzam o licenciando a exercitar, de forma ativa, a relação entre teoria e prática profissional docente, utilizando coleta de dados e diagnóstico sobre o ensino e a aprendizagem escolar, entre outras didáticas e metodologias;

II. Induzir a reformulação do estágio supervisionado nos cursos de licenciatura, tendo por base a experiência da residência pedagógica;

III. Fortalecer, ampliar e consolidar a relação entre a IES e a escola, promovendo sinergia entre a entidade que forma e a que recebe o egresso da licenciatura e estimulando o protagonismo das redes de ensino na formação de professores;

IV. Promover a adequação dos currículos e propostas pedagógicas dos cursos de formação inicial de professores da educação básica às orientações da Base Nacional Comum Curricular (BNCC) (BRASIL, 2018, p. 1).

As atividades da Residência Pedagógica são de formação, realizadas por um licenciando em uma escola de educação básica. Este Programa possui duração de 18 meses e uma carga horária total de 440 horas, divididas da seguinte maneira: 60 horas para ambientação na escola e 320 horas de 
imersão na escola. A carga horária de imersão da escola deve conter 100 horas de regência, incluindo: (a) o planejamento; (b) a execução de, pelo menos, uma intervenção pedagógica; e (c) a destinação de 60 horas para a elaboração de relatório final, da avaliação e da socialização de atividades (BRASIL, 2018). A Capes indica a seguinte divisão da carga horária dos 18 meses do programa: (1) 2 meses para a preparação dos residentes e para o início das atividades na escola campo; (2) 4 meses para ambientação escolar e para a elaboração do plano de atividades; (3) 10 meses para a imersão na escola; e (4) 2 meses para elaboração de relatório final, avaliação e socialização dos resultados.

Ao longo da imersão na escola campo, o licenciando deve planejar e executar uma intervenção pedagógica específica. A experiência da gestão da sala de aula deve ocorrer por meio de planejamento e da execução de atividades, planos de aulas, sequências didáticas, projetos de ensino avaliações da aprendizagem dos alunos. Podem participar do PRP os cursos de Licenciatura e tais cursos devem reconhecer a Residência Pedagógica para efeito de cumprimento do estágio curricular supervisionado (BRASIL, 2018). Vale destacar que a carga horária da residência pedagógica está em acordo com a diretriz do Conselho Nacional de Educação (CNE) para os cursos de Licenciatura, que estipula uma carga horária mínima de 400 horas para as atividades de estágio (BRASIL, 2015). Os residentes devem ter cursado ao menos $50 \%$ do curso, ou estar matriculado a partir do quinto semestre do curso - cronologia geralmente similar para a oferta das disciplinas de estágio nos cursos de Licenciatura.

Com isso, este trabalho apresenta o objetivo de relatar a diferença da experiência em docência entre os alunos do estágio curricular supervisionado com os alunos do Programa Residência Pedagógica e observar em quais pontos a experiência da residência poderia auxiliar no aperfeiçoamento dos estágios. 


\section{Metodologia}

Foi adotada nessa pesquisa uma metodologia qualitativa hipotética indutiva para a análise dos dados previamente coletados. Para tanto, foi escolhido um estudo de caso como ferramenta para a confecção do trabalho (LUDKE; ANDRÉ, 1986). A coleta de dados foi realizada com aplicação de questionários, sendo utilizados como amostra os alunos do Curso de Licenciatura em Química.

Para coletar informações sobre a experiência em docência de alunos do curso de Licenciatura em Química de uma instituição federal de ensino localizada no município de Luziânia-GO, aplicou-se um questionário aos graduandos que concluíram a etapa de experiência em docência. As respostas foram analisadas e agrupadas por categoria, de acordo com a repetitividade e relevância das ideias para o resultado da pesquisa.

O primeiro grupo de participantes foi composto de 15 alunos que concluíram a experiência em docência do curso pelas disciplinas obrigatórias de estágio curricular supervisionado. O questionário aplicado a esse primeiro grupo pode ser visto na Figura 1. Nesse curso, os estágios supervisionados com duração de dois anos e com uma carga horária total de 405 horas - são realizados nos últimos quatro semestres, divididos em quatro disciplinas.

O segundo grupo de participantes foi composto por 19 alunos que concluíram a experiência em docência do curso pelo Programa Residência Pedagógica. O questionário (Figura 2) abordou as mesmas ideias do questionário aplicado ao primeiro grupo. O curso de Licenciatura em Química da instituição participou do Programa Residência Pedagógica do edital Capes2018 com um total de 30 residentes, 3 professores preceptores, 3 escolas campo e 1 professor orientador.

Figura 1: Questionário aplicado aos alunos do curso de Licenciatura em Química que participaram do estágio curricular supervisionado.

\section{QUESTIONÁRIO}

1. O estágio correspondeu às suas expectativas?

Sim ( ) Não ( ) Por quê?

2. O estágio proporcionou o aprendizado de habilidades e competências profissionais e sociais necessárias ao exercício de sua profissão?

Sim ( ) Não ( ) Por quê?

3. Que dificuldade(s) você encontrou ao desenvolver suas atividades no estágio? 
( ) Nenhuma

( ) Relacionamento interpessoal

( ) Adequação da teoria à prática

( ) Falta de embasamento teórico

( ) Desconhecimento, de sua parte, das atribuições de sua futura profissão

( ) Falta de orientação/acompanhamento na Unidade Concedente

( ) Falta de orientação/acompanhamento do IFG

( ) Outro(s) Explicite:

4. Você considera o currículo do seu curso articulado às competências próprias da atividade profissional?

Sim ( ) Não ( ) Por quê?

5. Durante o período de estágio, houve contextualização curricular do conhecimento adquirido durante o curso?

6. Quais os componentes curriculares/competências que tiveram mais aplicabilidade durante o estágio?

7. Quanto à carga horária do estágio, você a considera:

Suficiente ( ) Curta ( ) Excessiva ( )

8. Em sua opinião, qual o interesse da unidade concedente ao oportunizar o estágio?

( ) Descobrir novos talentos com boa formação técnica

( ) Cumprir seu papel social, através da formação de novos profissionais

( ) Elo de ligação com as instituições de ensino e acesso a conhecimentos acadêmicos

( ) Ampliar e/ou renovar seus quadros funcionais

( ) Colaborador de baixo custo

( ) Outro. Especifique:

9. Ao concluir estágio, você gostaria de ser efetivado?

Sim ( ) Não ( ) Por quê?

10. Com base na experiência, aprendizado e convivência durante o período do estágio, você recomendaria esta concedente?

Sim ( ) Não ( ) Porquê ?

11. Faça suas críticas e sugestões para melhorar a gestão da Residência Pedagógica (encaminhamento, acompanhamento, orientação/supervisão, avaliação, entre outros).

Figura 2: Questionário aplicado aos alunos do curso de Licenciatura em Química que participaram do programa residência pedagógica.

\section{QUESTIONÁRIO}

1. A residência pedagógica correspondeu às suas expectativas?

Sim ( ) Não ( ) Por quê?

2. A residência pedagógica proporcionou o aprendizado de habilidades e competências profissionais e sociais necessárias ao exercício de sua profissão?

Sim ( ) Não ( ) Por quê?

3. Que dificuldade(s) você encontrou ao desenvolver suas atividades da residência?

( ) Nenhuma

( ) Relacionamento interpessoal

( ) Adequação da teoria à prática

( ) Falta de embasamento teórico

( ) Desconhecimento, de sua parte, das atribuições de sua futura profissão

( ) Falta de orientação/acompanhamento na Unidade Concedente

( ) Falta de orientação/acompanhamento do IFG

( ) Outro(s) Explicite:

4. Você considera o currículo do seu curso articulado às competências próprias da atividade profissional? 
Sim ( ) Não ( ) Por quê?

5. Durante o período da residência, houve contextualização curricular do conhecimento adquirido durante o curso?

6. Quais os componentes curriculares/competências que tiveram mais aplicabilidade durante a residência?

7. Quanto à carga horária do programa residência pedagógica, você a considera:

Suficiente ( ) Curta ( ) Excessiva ( )

8. Em sua opinião, qual o interesse da unidade concedente ao oportunizar a residência pedagógica?

( ) Descobrir novos talentos com boa formação técnica

( ) Cumprir seu papel social, através da formação de novos profissionais

( ) Elo de ligação com as instituições de ensino e acesso a conhecimentos acadêmicos

( ) Ampliar e/ou renovar seus quadros funcionais

( ) Colaborador de baixo custo

( ) Outro. Especifique:

9. Ao concluir a residência pedagógica, você gostaria de ser efetivado?

Sim ( ) Não ( ) Por quê?

10. Com base na experiência, aprendizado e convivência durante o período da residência pedagógica, você recomendaria esta concedente?

Sim ( ) Não ( ) Porquê ?

11. Faça suas críticas e sugestões para melhorar a gestão da residência pedagógica (encaminhamento, acompanhamento, orientação/supervisão, avaliação, entre outros).

Todos os alunos participaram de forma voluntária e anônima. Foram aplicados questionários impressos, sem a identificação dos alunos. Todos os licenciandos eram maiores de idade e todos preencheram um termo de consentimento livre e esclarecido (TCLE).

\section{Resultados e Discussão}

Analisando a primeira pergunta do questionário (o estágio correspondeu as suas expectativas?), todos os 15 estagiários (100\%) afirmaram que o estágio correspondeu às expectativas. Apenas três alunos justificaram suas repostas. Segundo a justificativa, mesmo não havendo interesse em seguir com a prática da docência, todos confirmaram que o estágio é de elevada importância para a formação dos futuros profissionais.

Por sua vez, os 19 estudantes residentes foram unânimes na resposta a essa mesma pergunta: o Programa Residência Pedagógica correspondeu às expectativas por ter proporcionado experiências e conhecimento para o futuro profissional. Algumas respostas podem ser destacadas: 
"Sim, porque me proporcionou aprendizado na prática" (aluno 1).

"Sim, para observar a dificuldade em ministrar as aulas com turmas lotadas e poucos recursos didáticos, e notar a importância, a preocupação e o esforço dos professores e funcionários para que a escola seja um lugar de aprendizado e de formação de cidadãos e futuros profissionais" (aluno 2).

Para essa questão, todos os alunos dos dois grupos - estagiários e estudantes residentes - acharam que a experiência em docência correspondeu às expectativas, contribuindo para a formação profissional, o que vai ao encontro com os dizeres de Pimenta e Lima (2017) sobre a importância dos estágios para a formação de professores. Além disso, nenhum residente chegou a afirmar a falta de interesse pela profissão, diferente do ocorrido com 3 alunos estagiários.

Para a segunda questão (o estágio proporcionou o aprendizado de habilidades e competências profissionais e sociais necessárias ao exercício de sua profissão?), todos os 15 estudantes acreditam que o estágio proporciona grande aprendizado no que tange as habilidades e competências para um professor, sendo que nenhum participante justificou sua resposta. Por seu turno, todos os 19 residentes afirmaram que a residência proporcionou grande aprendizado, e que a experiência de poder estar em sala de aula lhes trouxe importantes conhecimentos, principalmente no início da carreira. Algumas justificativas podem ser destacadas:

"Sim, porque aprendi muito nesse período, principalmente relacionamento interpessoal com os alunos" (aluno 2 ).

"Sim, pude perceber a realidade da educação" (aluno 3).

"Sim, pois tive a oportunidade em observa na prática como é a luta do docente no ensino de Goiás" (aluno 5).

Nota-se um maior entusiasmo dos residentes na descrição de sua experiência em docência, visto que todos os alunos justificaram suas respostas, fato não observado entre os alunos de estágio. Ademais, destaca-se o reconhecimento dos residentes pela importância da experiência em docência, mostrando que tal programa pode ter conseguido um elo entre a teoria e a prática, fato tão destacado pelo Conselho Nacional de Educação (BRASIL, 
2015), pela Capes (BRASIL, 2018), por Pimenta e Lima (2017) e Piconez e colaboradores (1991).

A terceira pergunta indaga as dificuldades que os alunos encontraram nas atividades de estágio e residência pedagógica. Dos 15 estagiários, 4 disseram que não encontraram dificuldade nenhuma; 3 citaram que tiveram problemas com relacionamento interpessoal com os alunos, com professores e com os servidores da escola campo; 4 alunos disseram que tiveram dificuldades com a adequação entre teoria e prática e 3 alunos citaram dificuldades no planejamento e na execução das aulas, pois julgaram o tempo para o preparo das aulas demasiadamente curto. Destacam-se uma justificativa:

"Eu planejei as minhas aulas de uma forma que fossem contextualizadas e, no mínimo, interessantes, apesar de que na prática eu não consegui realizar e aplicar tudo que eu havia planejado. Porém, a experiência não foi desagradável e nem totalmente improdutiva. Pelo contrário, consegui perceber a atenção dos alunos e consegui lhes ensinar um pouco de química" (aluno 7).

No grupo dos 19 residentes, 11 disseram não ter tido dificuldade em desenvolver as atividades da residência; 3 alunos disseram que tiveram problemas com relacionamento interpessoal; 1 aluno explicou que a maior dificuldade foi a lotação das salas e o comportamento dos alunos; e 4 residentes tiveram como dificuldade a falta de liberdade para ministrar as aulas, sendo impedidos de colocar em prática o conteúdo programado pelo professor regente.

É normal encontrar várias dificuldades no início do processo de ambientação da regência e os obstáculos enfrentados podem fazer com que o aluno perca o interesse pela docência. Entretanto, destaca-se o grande número de alunos, em ambos os grupos, que não relatou nenhuma dificuldade nas atividades de regência. A maioria dos residentes não declarou dificuldades nas atividades ou então não enxergou os diversos problemas inerentes à profissão. Além disso, sabe-se que os alunos que declararam ter enfrentado dificuldades foram unânimes em relatar que a experiência em sala de aula foi agradável. Também, 4 residentes afirmam a falta de liberdade para a regência, fato 
proporcionado pelo professor regular da turma. Piconez e colaboradores (1991) destacam a resistência de alguns professores da educação básica em receber alunos de estágio com metodologias diferenciadas e diversificadas. Consequentemente, os residentes tiverem pouca liberdade para trazer outras metodologias, tendo que voltar para as tradicionais aulas com apenas quadro e pincel. Este fato pode tornar a experiência de sala de aula não muito enriquecedora para os alunos.

Analisando a quarta pergunta do questionário (você considera o currículo do seu curso articulado com as competências próprias da atividade profissional?), todos os 15 estagiários consideram o currículo muito bem articulado, sendo que nenhum estudante justificou sua resposta. Dos 19 residentes que responderam às perguntas, 15 consideram que o curso é bem articulado e promove boa preparação de um futuro docente, além de proporcionar suficiente embasamento teórico. Todavia, quatro residentes acham que o curso é limitado e insuficiente para formar um bom profissional da educação, afirmando que, mesmo tendo muitas disciplinas na área da educação, faltam mais exercícios de práticas docente para preparar um bom professor para a atual realidade da educação.

Nota-se que a maioria dos estudantes de ambos os grupos acreditam que o currículo do curso de Licenciatura em Química apresenta uma boa articulação com as competências para a atividade docente. Entretanto, 4 alunos alegaram que sentem falta de mais práticas docente ao longo do curso. Nesse sentido, o Programa de Residência Pedagógica pode auxiliar nessa deficiência, visto que o programa apresenta uma carga horária total maior que a dos estágios supervisionados e conta com um substancial tempo de imersão na escola campo, permitindo maior contato e uma maior experiência em docência para os residentes. Vale destacar a importância da experiência profissional para a formação de professores (PIMENTA; LIMA, 2017). Segundo o edital da Capes para Residência Pedagógica (BRASIL, 2018), um dos objetivos do programa é permitir a reformulação dos estágios supervisionados com base na experiência da Residência Pedagógica. A maior carga horária e o 
maior tempo de imersão da escola de educação básica podem permitir uma futura análise sobre a experiência profissional do professor em formação.

Para a quinta pergunta do questionário (durante o período do estágio/residência, houve contextualização curricular do conhecimento adquirido durante o curso?), todos os alunos disseram que a maior parte do conteúdo é bem contextualizada com o currículo. Os alunos citaram as disciplinas da área de educação que tiveram elevada sinergia com a didática e as práticas pedagógicas aplicadas em sala de aula, podendo proporcionar aos discentes uma grande bagagem de teorias e metodológica. Já os residentes por sua vez, todos relataram que houve contextualização curricular do conhecimento adquirido ao longo do curso, mas não justificaram a resposta e nem destacaram disciplinas nesse processo.

Analisando a sexta pergunta do questionário (quais os componentes curriculares/competências que tiveram mais aplicabilidade durante 0 estágio/residência?), todos os alunos compreenderam que as disciplinas da área do curso foram essenciais na prática da sala de aula, citando algumas disciplinas da área de Química, tais como Química dos Elementos, Transformações Químicas e Estrutura e Propriedades da Matéria curiosamente as disciplinas do início do curso - e também disciplinas pedagógicas, como Didática, Psicologia da Educação e Organização e Gestão do Espaço Educativo. Um dos alunos citou a falta de autonomia por parte do professor diante do currículo do estado de Goiás. Algumas respostas apresentadas foram:

"Principalmente as que estão ligadas a sala de aula, além de disciplinas como química dos elementos, organização e gestão do espaço educativo e teorias da educação" (aluno 5).

"Disciplinas como didática, metodologia do ensino de química e psicologia da educação" (aluno 11).

Analisando as respostas para a mesma pergunta dos 19 alunos do programa residência pedagógica, 15 citaram a disciplina de Didática como sendo a de maior aplicabilidade na sala de aula. Na sequência, os alunos citaram também outras disciplinas, como Metodologia do Ensino, Oficina do Ensino de Química, Transformações Químicas e Química Orgânica. Nota-se 
uma grande similaridade nas respostas dos dois grupos de alunos. Ambos afirmaram a importância das disciplinas técnicas e das disciplinas pedagógicas, mostrando a importância da interdisciplinaridade para a formação do professor. É de grande importância que se tenha um elo entre as disciplinas de Química e as disciplinas pedagógicas, assim como deve haver uma constante união entre a teoria e a prática (PIMENTA; LIMA, 2017).

A sétima pergunta indaga sobre a carga horária do estágio e da residência. Todos os estagiários afirmaram que a carga horária dos estágios supervisionados é suficiente. Em relação aos alunos da residência pedagógica, 17 dos 19 alunos consideram ser suficiente a carga horária da residência e relatam que as horas de experiência e contato direto com os alunos em sala de aula são importantes para sua futura profissão. Apenas 2 alunos disseram ser insuficiente, mas não explicaram o motivo. As respostas dos alunos estagiários para as questões 4 e 7 foram contraditórias, visto que eles relatam falta de prática docente ao longo do curso, mas afirmam que a carga horária de estágio está suficiente. Vale relembrar que o estágio supervisionado possui carga horária total de 405 horas e atende a diretriz do Conselho Nacional de Educação de um mínimo de 400 horas (BRASIL, 2015). Também, todos os estagiários estão de acordo de que a carga horária para a prática docente foi suficiente. No que concerne à residência pedagógica, mesmo possuindo carga horária de $440 \mathrm{~h}, 10 \%$ dos alunos alegaram que a carga horária foi insuficiente para a sua formação.

Para a oitava pergunta (em sua opinião, qual o interesse da unidade concedente ao oportunizar o estágio?), os alunos estagiários se dividiram entre duas afirmações principais: (a) 8 disseram que o interesse da unidade concedente é fazer um elo com instituições de ensino superior e acesso ao conhecimento acadêmico; e (b) 7 afirmaram que o interesse da unidade concedente é cumprir o papel social por meio do incentivo na formação de novos profissionais. Já os alunos da residência se dividiram em 3 três respostas principais: (a) 5 consideram que o interesse da unidade concedente ao oportunizar a residência seria fazer um elo entre a escola e a as instituições de ensino superior; (b) 7 consideram que o interessante é descobrir novos 
talentos com boa formação técnica; e (c) 7 consideram que a unidade concedente apenas procurou cumprir seu papel social por meio da formação de novos profissionais. Um grande número de licenciandos destacou o interesse da escola em promover um elo com instituição de ensino superior, o que comprova a sinergia entre as instituições envolvidas no programa (BRASIL, 2018). Além disso, é de grande interesse essa relação, visto que várias pesquisas que ocorrem nas universidades são voltadas para a educação básica e, muitas vezes, os professores da educação básica não possuem acesso a tais pesquisas. Essa ponte entre IES e escola da educação básica pode ser um passo importante para uma melhora na qualidade do ensino básico.

A nona pergunta do questionário abordava se os alunos gostariam de ser efetivados na escola campo após concluir o estágio/residência. Para os alunos estagiários, observou-se que 11 alunos gostariam de ser efetivos e seguir a carreira docente, ao contrário dos outros 4 alunos que não gostariam de ser efetivados na escola em que realizaram o estágio supervisionado. Podese destacar algumas justificativas:

"Sim, apesar de todos os desafios de ser professor, dos problemas das escolas públicas e da desvalorização sofrida pelo professor no país, promover o ensino de química é gratificante" (aluno 8).

"Sim, pude me identificar bastante com a profissão pelo fato de poder compartilhar conhecimento com meus alunos. O estágio trouxe experiências significativas para decidir seguir nesta carreira" (aluno 9).

"Não, porque já tenho carreira na indústria e, neste momento, não tenho certeza de exercer a carreira docente" (aluno 13) e "não, porque já tenho outra área de trabalho definida, mas no futuro, seria uma boa ideia" (aluno 15).

Para os alunos residentes, 16 afirmaram que gostariam de ser efetivados e seguir a carreira de professor, dentre os quais 7 afirmaram que a residência pedagógica influenciou nessa decisão. Em contrapartida, 3 alunos disseram não querer ser efetivados, sendo que o primeiro justificou já ter uma profissão; o segundo afirma que não quer ser professor; e o terceiro pensa em seguir na indústria. Nota-se que a maioria dos alunos, tanto estagiários, como 
residentes, gostariam de ser efetivados na escola e seguir as atividades no magistério. Além disso, houve relatos de que o estágio e a residência influenciaram na decisão em querer ser professor, destacando a importância que a experiência na docência ao longo da graduação pode trazer para o ensino.

Para a questão de número dez (com base na experiência, aprendizado e convivência durante o período do estágio/residência, você recomendaria essa concedente?), 13 alunos estagiários recomendariam as escolas estaduais concedentes do estágio supervisionado. Citaram que foram bem recebidos e que algumas escolas inclusive os incentivaram a docência. Apenas dois alunos alegaram não recomendar a escola concedente de estágio em função da desorganização da mesma. Por sua vez, todos os 19 residentes recomendariam a escola concedente, pois consideraram que foram bem acolhidos. Apesar dos problemas inerentes nas escolas públicas, percebe-se que a maioria dos alunos recomendariam o trabalho na escola, acreditando na importância que o ambiente educacional possa desempenhar para a sociedade e para a realidade local. Também, vale a pena lembrar que, no programa residência pedagógica, os alunos foram distribuídos em três escolas previamente selecionadas por um edital, fato não observado nos estágios, em que os alunos estavam distribuídos em oito escolas aleatoriamente selecionadas. Esse fato pode auxiliar na compreensão da justificativa dos residentes, visto que todos recomendaram as escolas campo. Como as escolas campo do estágio são, em muitos casos, escolhidas pelo próprio aluno, nem sempre eles as recomendam como apontado nas respostas do questionário.

Analisando a questão onze do questionário, 11 dos 15 estagiários não fizeram sugestões e nem críticas, apenas afirmaram que o estágio deveria ser mantido da forma como é organizado atualmente. Contudo, quatro estudantes apresentaram sugestões e críticas. O primeiro sugeriu que a gestão do estágio aprimore os critérios de seleção das escolas concedentes e que amplie a disponibilidade de horários dos estágios, pois muitos estudantes trabalham durante o dia e cursam o Ensino Superior no período noturno. O segundo aluno sugeriu que o professor da disciplina possa assistir algumas aulas que os 
discentes ministram na escola campo, uma vez que, na opinião do estudante, os colegas preparariam e ministrariam as aulas com melhor qualidade. Todavia, deve-se destacar uma impossibilidade logística do professor de estágio em assistir as aulas, pois os alunos são distribuídos em diferentes escolas, com horários e dias diferentes. Por fim, o terceiro aluno sugeriu que as regências de aulas comecem já no estágio II, antecipando a preparação dos alunos. O quarto aluno sugeriu um aprimoramento do curso no que concerne à inclusão, pois o conteúdo programático ensinado ao longo da graduação mostrou-se insuficiente com as necessidades do cotidiano de um professor. $\mathrm{O}$ curso conta com apenas uma disciplina (Libras) voltada para o ensino de alunos com necessidades especiais, mostrando a carência na formação.

Em relação a afirmação do primeiro aluno, a seleção das escolas para o estágio precisa ocorrer de forma mais direta, visto as frequentes reclamações dos estagiários em relação a escola. Este fato não é observado no programa residência pedagógica, em que apenas três escolas são selecionadas por um edital de seleção. Nesse aspecto, a experiência da residência pedagógica pode contribuir para a reformulação dos estágios supervisionados, conforme é indicado pela Capes (BRASIL, 2018). Em relação a afirmação do segundo aluno, destaca-se a dificuldade e disponibilidade do professor de estágio acompanhar todos os alunos, visto que os mesmos ficam distribuídos em vários dias e horários diferentes, fora o grande número de escolas envolvidas. Esse fato já não foi observado na residência pedagógica, em que os alunos ficam distribuídos em menos escolas, o que facilita o acompanhamento pelo professor, fato que a residência pode contribuir novamente para o aperfeiçoamento dos estágios. Para os comentários do terceiro aluno, esse afirma a importância de começar a regência mais cedo, para ter mais experiência em sala de aula, e esse fato também é corrigido na residência pedagógica, visto o maior tempo de imersão do residente na escola campo. $O$ quarto aluno aponta a necessidade para uma preparação, ao longo da formação, para trabalhar com alunos com necessidades especiais, e o currículo do curso precisa atender a tal apontamento. O curso conta com apenas uma disciplina (Libras) voltada para o ensino de alunos com necessidades 
especiais, mostrando que o curso ainda carece em ter uma formação adequada para a afirmação.

No tocante à opinião dos residentes, 16 não tinham críticas e sugestões, e 03 alunos elencaram elogios às atividades do programa, tais como:

"Não tenho o que sugerir, e sim elogiar, pois os professores sempre se mostraram dispostos a tirar as dúvidas e ajudar" (aluno 1).

"O programa é muito organizado e temos uma boa comunicação com os supervisores. No meu ponto de vista, o programa é excelente" (aluno 2).

"Neste tempo pude aprender muita coisa em sala de aula, mudando bastante minha opinião enquanto professora" (aluno $3)$.

Notou-se que o Programa Residência Pedagógica teve boa aceitação entre os alunos, agradando a maioria dos residentes. A boa aceitação pode ser explicada pelo fato de o aluno não ser obrigado a participar do programa; por sua vez, o Estágio Supervisionado é um requisito obrigatório para conclusão do curso. Ademais, os residentes recebem uma bolsa de $R \$ 400,00$ mensais ao longo dos 18 meses do programa e os alunos de estágio supervisionado não são remunerados pela sua participação.

Notou-se certa similaridade nos relatos de experiência em docência dos alunos que participaram dos estágios supervisionados com os alunos que participaram do Programa Residência Pedagógica. Vale destacar que, segundo o edital da Residência Pedagógica (BRASIL, 2018), a Instituição de Ensino Superior deve reconhecer a Residência Pedagógica como Estágio Supervisionado, com isso, pressupõe-se a que deve existir semelhança das atividades nas duas propostas. Entretanto, nota-se que em alguns aspectos, a experiência do Programa Residência Pedagógica pode ser utilizada para aperfeiçoar as práticas do Estágio Supervisionado.

\section{Conclusão}

Os estudantes dos cursos de licenciatura encontram dificuldades na relação dialética entre teoria e prática de ensino. Contudo, essas dificuldades 
podem ser superadas por meio dos estágios, que são oportunidades para comprovar que esses dois elementos devem caminhar sempre juntos.

Entrar em uma sala de aula pela primeira vez não é uma tarefa fácil e sem o devido preparo pode acarretar grandes prejuízos no processo de ensino e aprendizagem, bem como uma desmotivação para o futuro professor. Este preparo deve ser o objetivo principal dos estágios supervisionados na docência e do Programa Residência Pedagógica. Uma boa formação inicial, somada à experiência em sala de aula, pode resultar em uma educação de qualidade.

Os estágios supervisionados e a residência pedagógica apresentam um objetivo principal comum: trazer a experiência na educação básica para o licenciando. Notou-se que os alunos que participaram do estágio supervisionado relataram a experiência em docência de forma similar aos alunos que tiveram essa etapa pelo programa residência pedagógica. Entretanto, observou-se que a experiência do Programa Residência Pedagógica pode ser uma excelente oportunidade para aperfeiçoar as atividades do estágio curricular. Em tempos de tamanho desprestígio e desvalorização do professor, programas que incentivem a carreira docente podem ser de grande importância para o futuro da educação no país.

\section{Agradecimentos}

Os autores gostariam de agradecer a Capes pelo apoio financeiro.

\section{Referências}

BRASIL. Ministério da Educação. Resolução do Conselho Nacional de Educação - CNE/CP n 2, de 01 de Julho de 2015 - Diretrizes Curriculares Nacionais para a formação inicial em nível superior (cursos de licenciatura, cursos de formação pedagógica para graduados e cursos de segunda licenciatura) e para a formação continuada, 2015.

BRASIL. Coordenação de Aperfeiçoamento de Pessoal de Nível Superior CAPES. Edital CAPES n 06/2018 - Programa de Residência Pedagógica, 2018.

FARIA, J. B.; PEREIRA, J. E. D. Residência pedagógica: afinal, o que é isso? Revista Educação Pública, v. 28, n. 68, p. 333-356, 2019. 
FREIRE, P. Pedagogia do Oprimido. Rio de Janeiro: Paz e Terra, 2013.

GARCEZ, E. S. C. et al. O Estágio Supervisionado em Química: Possibilidades de Vivência e Responsabilidade com o Exercício da Docência. Alexandria, v. 5, n. 3, p. 149-163, 2012.

GUEDES, M. P. A Nova Política de Formação de Professores no Brasil: Enquadramentos da Base Nacional Comum Curricular e do Programa de

Residência Pedagógica. Da Investigação às Práticas, v. 9, n. 1, p. 90-99, 2019.

KASSEBOEHMER, A. C., FERREIRA, L. H. O Espaço da Prática de Ensino e do Estágio Curricular nos Cursos de Formação de Professores de Química das IES Públicas Paulistanas. Química Nova, v. 31, n. 3, p. 694-699, 2008.

LUDKE, M.; ANDRÉ, M. E. D. A. Pesquisa em educação: Abordagem qualitativas. São Paulo: Editora Pedagógica e Universitária, 1986.

PICONEZ, S. C. B. et al. A Prática de Ensino e o Estágio Supervisionado. São Paulo: Papirus Editora, 1991.

PIMENTA, S. G.; LIMA, M. S. L. Estágio e Docência. São Paulo: Cortez, 2017.

SILVA, R. M. G.; SCHNETZLER, R. P. Estágios Curriculares Supervisionados de Ensino: partilhando experiências formativas. EntreVer, v. 1, n. 1, p. 116136, 2011.

\section{Sobre os autores}

\section{Francisca Cassia Sousa dos Anjos}

cassiasouzadosanjos@gmail.com

Licencianda em Química pelo Instituto Federal de Educação, Ciência e Tecnologia de Goiás (IFG), campus Luziânia.

\section{Oséias Soares Ferreira}

oseias.soares.ferreira@gmail.com

Mestre em Educação (2018) pela Faculdade de Educação - Unicamp. Graduado em Pedagogia (2010) pela Faculdade do Noroeste de Minas e em História (2007) pela Faculdade DOCTUM. Especialização em História Social e Contemporânea (2018), Educação Profissional Integrada a Educação de Jovens e Adultos PROEJA (2013) e Especialização em Gestão Educacional (2008). Atualmente é Doutorando no Programa de Pós-graduação em Educação da FE - Unicamp (2019). É Professor do Instituto Federal de Educação, Ciência e Tecnologia do Espírito Santo - IFES. 


\section{Diego Arantes Teixeira Pires}

diego.pires@ifg.edu.br

Possui graduação em Química (Bacharelado) pela Universidade de Brasília (2010), graduação em Química (Licenciatura) pela Universidade de Brasília (2010), mestrado em Química pela Universidade de Brasília (2012) e doutorado em Química pela Universidade de Brasília (2016). Atualmente é professor do Instituto Federal de Educação, Ciência e Tecnologia de Goiás, campus Luziânia. 